is not a new one. The debate over professional image has prevailed in our literature and on our coffee breaks. As a program for the Spring Meeting of the
Washington State Chapter of ACRL, it offered a formal arena for substantive discussion and decision-making.

\title{
A coordinated program for state agricultural publications
}

\author{
By Sarah E. Thomas \\ Chief, Technical Services Division \\ National Agricultural Library
}

\section{A cooperative project of the National Agricultural Library and land-grant university libraries.}

B cations is one of the most challer cations is one of the most challenging tasks facing documentalists and agricultural librarians today. State Agricultural Experiment Station and Extension Service publications contain valuable information on scientific research and practical application of that research which is important for researchers and consumers. Yet, because of the difficulties inherent in tracking and providing access to this literature, the information contained in these publications has been severely underutilized.

Librarians have long recognized that control of state publications is even more elusive than that of federal documents, and they are not used as frequently as federal publications. ${ }^{1}$ Terry Weech, a documents specialist, observed that "state government information sources are often considered secondary in importance to national and international information sources." 2 Yet these publica-

\footnotetext{
${ }^{1}$ David W. Parish, "Some Light on State Bibliographies," Government Publication Review 12 (January-February 1987): 65-70.

${ }^{2}$ Terry I. Weech, "Introduction," Government Publications Review 10 (March-April 1985): 155.
}

tions contain useful information, and there is some evidence that enhancing access, for example, including records for government publications in an online catalog, significantly increases their level of use.

The route to providing access to state agricultural material is fraught with peril at every turn. Acquisition of state agricultural publications can often be a haphazard process, as some agencies responsible for distribution of this literature issue publications in limited numbers, do not automatically include libraries on their mailing lists for distribution, and publish without observing bibliographic conventions with regard to attribution and identification of which series a particular title should be issued in. For the acquisitions librarian, the task of obtaining this often fugitive literature can require great patience, perseverance, and ingenuity.

Once the material has been acquired for the library, serial checkers and catalogers face additional problems. State agencies sometimes drop, consolidate, and rename titles without adequate announcement, making the tracing of their bibliographic history confusing, complicated, or even 
impossible. Seemingly undecipherable numbers appear on the covers of the publications, leaving the librarian in doubt as to whether they are meaningful bibliographic clues, or simply some agencyrelated code. Considerable authority work usually awaits the cataloger, and it is rare that the document already has cataloging copy available in a bibliographic utility. Some of the publications, particularly those issued by the Extension Service, are brief and scarcely seem to justify the expense of full-level cataloging. All too frequently, state agricultural publications languish on a cataloger's problem shelf, or are consigned to a low priority backlog. Some institutions do not provide bibliographic access to state documents at all, relying instead on the Monthly Catalog of State Publications, published by the Library of Congress, or other indexes to government documents. In short, bibliographic control of state agricultural publications is a time-consuming and often arduous process.

The difficulty in acquiring and cataloging state Extension Service, Experiment Station, and other agriculturally related state publications compounds the document delivery process as well. There is limited access to holdings information for these documents, and one cannot always be certain which source to seek out to obtain copies of the documents. It is not always possible to go directly to the Extension Service or the Experiment Station, and libraries either have had no policy on maintaining archival copies of this material or are not sufficiently aware of their policies. Locating and delivering a copy of a particular item was consequently not an easy assignment.

In 1984, in response to the problems associated with maintaining control over state agricultural publications, Joseph Howard, director of the National Agricultural Library (NAL), conceived of a plan for a coordinated program to control state agricultural literature. NAL's collection development policy called for comprehensive collection of state agricultural documents, and these materials, once acquired, were either cataloged on OCLC or indexed in-house, with both cataloging and indexing records being contributed to NAL's AGRICOLA database. Despite this policy, however, gaps were frequently detected in the collection, and access to the documents on hand was also spotty. Howard reasoned that individual states would have a primary interest in collecting and providing access to agricultural titles issued within their boundaries, and that the land-grant library for a particular state would be the logical center. If the land-grant libraries and NAL could cooperate in a network which aimed at each state assuming responsibility for bibliographic control of its own agricultural publications, with NAL serving as backup and as national and international disseminator of bibliographic citations to the material, the entire agricultural community of the United States and the world would be better served.
With such an idea in mind, NAL solicited support from land-grant university librarians in December 1984. Essentially, NAL's proposal was for the land-grant university library in each state to acquire copies of state agricultural documents for itself and for NAL, to catalog those items appropriate for full-level cataloging, and to serve as the primary source for requests for this material. Participating libraries would forward copies of each publication to NAL to add to its collection, accompanied by a print-out of its cataloging record. NAL would supplement the record with AGRICOLA category codes and its own local information, such as call number, and would index those publications which the land-grant university library had not found suitable for cataloging at its own institution. Records for all items would be incorporated in the AGRICOLA database, making AGRICOLA the strongest source for citations to state agricultural literature. NAL would also contribute records for these documents to FAO's AGRIS database, further increasing their worldwide access. Cooperating libraries agreed to provide document delivery on titles for their state, while NAL pledged to serve as backup.

NAL's proposal was founded on the belief that cooperative activities demonstrate that the sum is greater than its parts. Through a coordinated plan, the workload for management of state agricultural publications would be evenly distributed, with those parties having a strong self-interest in the material taking the leadership role for its control and access. Furthermore, it stood to reason that the land-grant university libraries, being closer to the source of emanation for the publications, would be in a position to know of the existence of and to obtain what was frequently fugitive literature. Often these publications offices were located directly on university campuses. NAL, at a distance, was at a disadvantage in trying to collect these materials comprehensively. By the time it learned of a particular title, perhaps through a patron's request, the printing was exhausted, leaving an unfillable gap in NAL's collection. In addition, when land-grant librarians committed themselves to acquiring and providing priority cataloging for state agricultural titles, NAL would be able to redirect its resources towards the acquisition and processing of other U.S. agricultural publications, including those of the United States Department of Agriculture, for which it has primary collection and processing responsibilities. This in turn would benefit the landgrant community and others needing access to agricultural information. In concrete terms, NAL estimated that if each state contributed twenty cataloging records for which NAL would have previously provided original cataloging, NAL would have the equivalent of one fulltime employee to devote to other activities. A relatively modest investment by the land-grant institution would lead to substantial advantages for many others.

Like many other coordinated cooperative activi- 


\section{ACQUISITION PERSPECTIVES}

2. Book House guarantees to order each book you request, with regular claiming to publishers. From major publishers on open account to the most obscure press requiring prepayment and offering no discount, our persistence and experience enables us to deliver every available title.

There is no substitute for complete delivery.

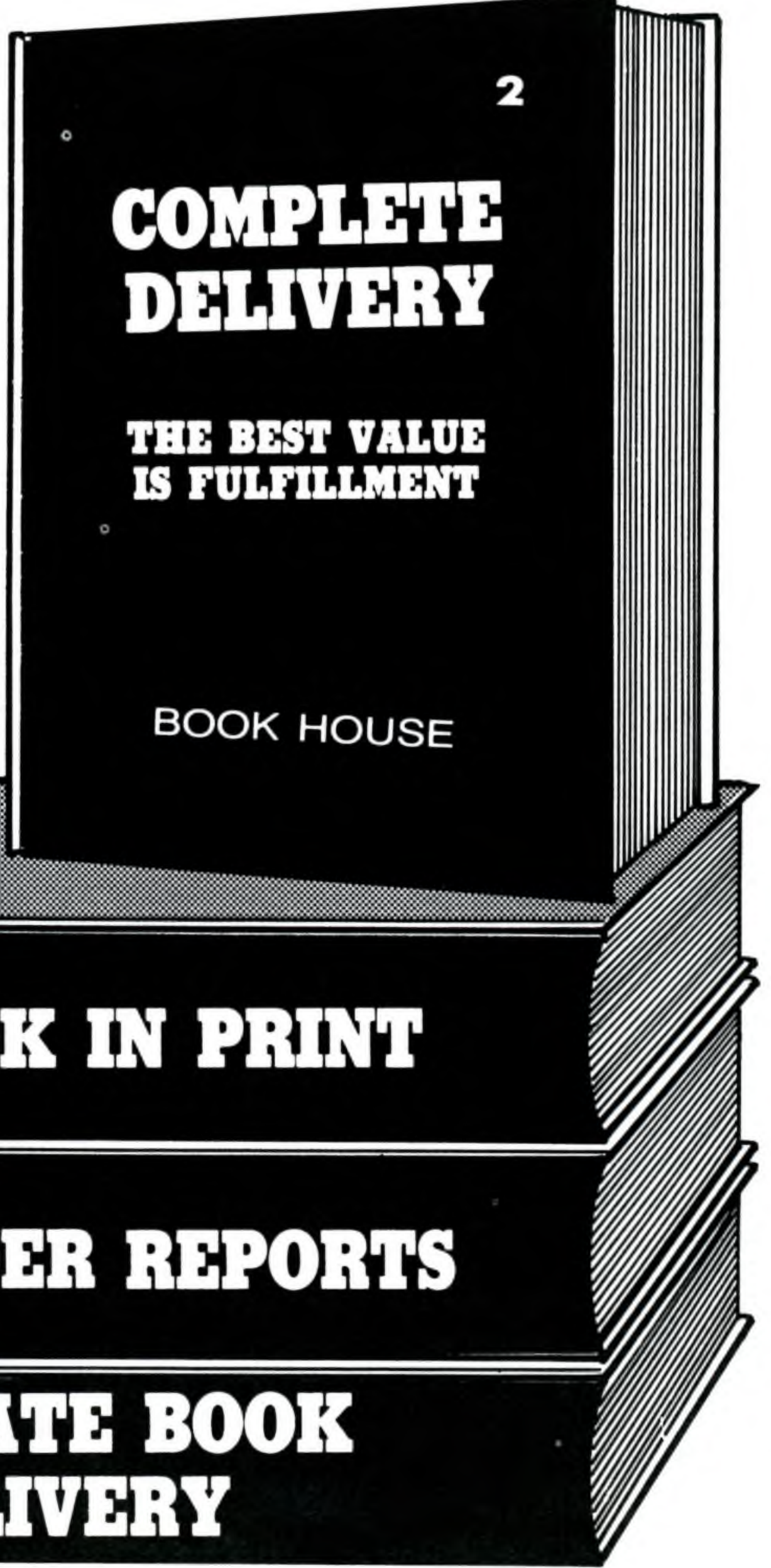

CALL TOLL-FREE TODAY

1-800-248-1146

In Canada \& Michigan

CALL COLLECT (517) 849-2117

OCLC Vendor No. 17397

SAN 169-3859

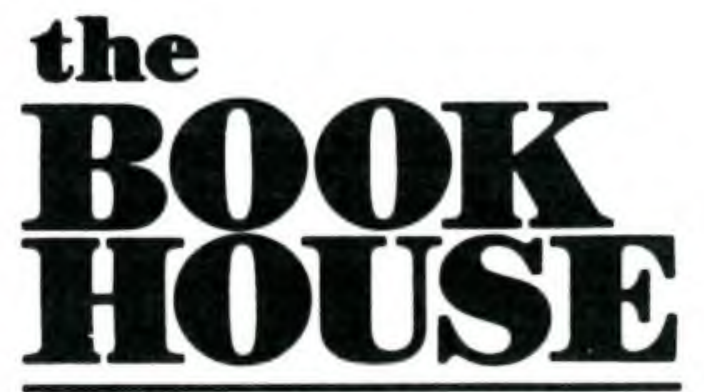

JOBBERS SERVING LIBRARIES WITH ANY BOOK IN PRINT SINCE 1962 208 WEST CHICAGO STREET JONESVILLE, MICHIGAN 49250 
ties, such as CONSER (Cooperative Online Serials) or NACO (National Coordinated Cataloging Operations), the concept is simple, and easily supported in principle, but the actual implementation is complex. Local practice and local needs vie with national level standards and priorities. Library administrators embrace policies which operational level staff may not readily support. Even twenty additional records a year, or a change in cataloging priority can be a burden for a staff already fully committed to other projects. In some states, several institutions share responsibility for collecting state documents. In Alabama for example, Auburn University, a land-grant university, collects Experiment Station materials, while Alabama A \& $\mathrm{M}$ and Tuskegee Institute and University collect other state agricultural publications. Colorado State University Library reported that the Colorado State Library had primary responsibility for providing access to state literature, and as a consequence CSU has a policy of relying on the State Library for its cataloging.

Even if there was willingness to participate in the project, there was still a great deal of uncertainty about what materials were in scope. Were all Extension Service publications, even mimeographed handouts, to be included in the project? What about audiovisuals and computer software? Many other agriculturally-related publications were issued outside the purview of the state Extension Service or the Experiment Stations. Were titles published by the Water Resources Board or the Division of Plant Industry also to be acquired? The answer to these queries was affirmative: the project was to aim at comprehensive coverage of state agricultural documents, although the logical focus at outset was the Experiment Station and Extension Service publications, since these were partially funded by USDA, NAL's parent organization.

In addition to questions of responsibility and scope, there were many other unclear areas. Would NAL pay postage on the shipments? NAL considered that negotiable, depending on the size and volume of the packages. Could NAL accept an OCLC or RLIN number rather than a printout? Anything was better than doing original cataloging, although a printout speeded up processing. Any record, from any bibliographic utility was acceptable. How often were the shipments to be sent? This was up to the sending institution, although at least quarterly shipments would be desirable. Some organizations were reluctant to disturb existing mailing lists which sent pieces directly from the publishing agency to NAL: they felt the potential for disruption of service to be greater than the advantage gained by NAL of having the piece and the printout matched together at their library. NAL wanted to be as flexible as possible during the early phases of the program to facilitate participation. Consequently, NAL and various land-grant university librarians agreed on a number of individualized arrangements.
Who decided what was cataloged and what was indexed? NAL established some rough guidelines for itself, and shared these with its cooperators. In general, series in which at least $60 \%$ of the titles were substantive monographs of fifty or more pages were selected for cataloging, as well as research-oriented series, such as experiment station bulletins, technical bulletins, water resource reports, research bulletins, or economics reports. Most other items in series, including most Extension Service publications and pamphlet type materials under fifty pages, were destined for indexing, a much less expensive method of providing bibliographic access at NAL. Was the project only for prospective receipts, or did it include retrospective materials? To make the project manageable, only prospective titles were slated for inclusion. A myriad of questions surfaced as librarians moved beyond the initial commitment to the implementation stage.

For the near term, NAL as the project coordinator has attempted to impose as few restrictions on participating librarians as possible, with the idea that as the procedures became more routine, librarians would be able to increase their contributions. As a rule, the preference is to include all materials and all formats in the project. The University of Florida Central Science Library is an example of an ideal partner in the state agricultural publications project. At the start of the project, the Cataloging Branch of the National Agricultural Library prepared an inventory of Florida state agricultural publications which were held at NAL. The list had the titles of nine agricultural series published by such agencies as the Florida Cooperative Extension Service, the University of Florida Agricultural Experiment Station, and the University of Florida Agricultural Research Center, with an indication as to whether publications appearing in these series were cataloged or indexed by NAL. Although the University of Florida Central Science Library was not obligated to supply all items appearing in these series or to provide cataloging in accordance to NAL's cataloging practice, NAL suggested that the library review the list, provide copies of the piece and cataloging printouts for titles sent, and to augment the list with other titles not held by NAL. The University of Florida has been unflagging in its support of the program. The University of Florida Library staff catalogs newly issued materials promptly and sends a record of the cataloging along with two copies of the piece for NAL. Document delivery of Florida state publications is provided routinely. In addition, Florida has undertaken an active role in supplying retrospective materials to fill gaps in NAL's Florida State agricultural documents holdings.

Altogether, forty land-grant libraries have agreed to participate in the NAL-Land-Grant cooperative program, and ten others are considering lending their support. Only one library has responded negatively, and that institution has of- 
fered to reconsider once pressing internal needs lessen. A few librarians have seized the NAL-Land-Grant State Agricultural Publications program as an opportunity to reevaluate their control over their state's agricultural materials. One especially enterprising and concerned librarian, John Beecher, director of the North Dakota State University Libraries, took NAL's proposal to the administration of the College of Agriculture to obtain funding enabling NDSU to become a full participant in the cooperative endeavor. Beecher's appeal for assistance was successful, and consequently he anticipates that NDSU will be able to increase the number of North Dakota agricultural titles that will be included in AGRICOLA, NDSU's online catalog, and in OCLC. Beecher also envisions adding occasional monographic publications from the North Dakota State Department of Agriculture and the North Dakota Wheat Commission.

Another library was creative in preparing a proposal to the U.S. Department of Education. The agricultural librarian of the University of Illinois, Carol Boast, successfully applied for a Title II-C grant to establish a retrospective cataloging and indexing program to strengthen the research collections of the University of Illinois Agriculture Library and to improve national and international access to hard copy sets of United States Department of Agriculture materials from 1862 to the present through series analytics on the OCLC database and indexing on the AGRICOLA and AGRIS databases. Through a cooperative agreement with the National Agricultural Library, the University of Illinois Agriculture Library has contributed 16,149 records as of October 1987 for inclusion in AGRICOLA. The second phase of the project, beginning in 1988, will focus on retrospective state Experiment Station publications. This activity complements the ongoing NAL-Land-Grant State Publications Program well, increasing the comprehensiveness of coverage significantly.

In another cooperative arrangement with the National Agricultural Library, the University of Kentucky Agriculture Library has contributed records for one hundred years of Kentucky State Agricultural Experiment Station documents to the AGRICOLA database. Talks are also underway with administrators in two libraries in the University of California system, Berkeley and Davis, to adapt information on California State publications going into a local PC-based file for use in AGRICOLA. Records exist in manual form for almost thirty years of agricultural documents, and plans call for retrospective conversion of these titles and for implementation of a system to enter prospective materials into AGRICOLA.

NAL and the cooperating land-grant institutions are gradually attaining the goal of the project, that of increased access to state agricultural literature. In 1984 , over 5,384 records for state agricultural documents, including state agricultural Experi- ment Station bulletins, reports, and state Extension Service publications, were added to the AGRICOLA database. During 1985, the year the project was in its infancy, this number actually decreased to 4,420 . The following year, 1986, saw sharp growth to 6,424 records. Projected figures for 1987 promise a steady incline. This increase comes even in the face of an overall decline in state publications, indicating that even higher percentages of state agricultural documents will be accessible in the AGRICOLA and AGRIS databases.

By the end of 1986, the National Agricultural Library had identified 287 agricultural titles published by the contributing states. During the first ten months of 1987, participating land-grant libraries have located and supplied 46 additional titles, a $16 \%$ increase, and a strong indication that the original objective of the NAL-Land-Grant State Publications Program is being met. Clearly, bibliographic control over this valuable research and information is increasing, and the OCLC, AGRICOLA, and AGRIS databases in particular are being enriched. Yet the room for improvement remains vast.

In 1988, NAL and the land-grant university libraries can expect to see several further developments. Additional land-grant libraries will commit support to the program, and those already participating will increase their level of contributions. More non-traditional materials such as software and audiovisuals will be incorporated into the processing. The scope of the project may be expanded to include agricultural theses and dissertations completed for degree requirements at landgrant universities. There is interest in working on a similar program with sea-grant institutions. The National Agricultural Library will review its receipts to determine if it is more effective to receive publications directly from state agencies or from land-grant university libraries, or if a combination approach is more successful in obtaining the most comprehensive coverage possible. Preliminary investigations reveal that there is almost no overlap between titles received directly at NAL and those supplied by the land-grant university libraries. It seems clear that the program will increase coverage of unique materials.

Last year, in excess of $\$ 3$ billion dollars was spent by state agencies on agricultural research and applications. The State Cooperative Extension Service alone had a budget of $\$ 728.6$ million, and the Cooperative State Research Service spent $\$ 741.7$ million in 1986. The publications budgets for state agricultural agencies is estimated to exceed $\$ 30$ million dollars. It is essential that this investment in research, practical applications and the dissemination of print and audiovisual information emanating from these endeavors be made more fruitful by ensuring that the broadest and largest community possible have access to these valuable and useful publications. Through the coordinated program for the acquisition, cataloging, and document de- 
livery of state agricultural publications by the $\mathrm{Na}$ tional Agricultural Library and the state landgrant university libraries, such access is now a reality.

Author's note: No copyright is claimed on this article, which the author wrote as a part of her offi- cial duties as an employee of the United States Government. The author would like to thank Idalia Acosta, Martha Hood, and Karl Schneider of NAL for their assistance in providing statistical data as background for this paper.

\title{
Magazine Index Plus or
}

\section{Academic Index?}

\author{
By Christine H. Guyonneau \\ Reference Librarian \\ University of Indianapolis
}

\section{A comparison of two major INFOTRAC databases.}

$\mathbf{F}$ Limited university and college libraries with limited budgets, innovative technology is often prohibitively expensive, and choosing the best available database to fill the needs of the community often brings a dilemma. Aware of this problem, Information Access Company (IAC) offered an attractive alternative to institutions that could not afford the purchase of its INFOTRAC database: it marketed a smaller database, INFOTRAC II, which indexed about one-third of the journals contained in INFOTRAC and which IAC named Magazine Index Plus. Like its parent counterpart, Magazine Index Plus operates on a CD-ROM. The laser disk is updated monthly, and the journals are indexed as far back as 1983. It also covers the last 90 days of the New York Times. However, one of the major drawbacks of this IAC product for any academic library is the lack of scholarly titles. The majority of the journals indexed can be found in Reader's Guide to Periodical Literature. If this type of information can be useful to the first-year student getting acquainted with the research process, it was its limitations for the senior, the honors student and even more so for graduates who will not find bibliographic citations to People Weekly, Audio or $M s$ appreciated by their thesis advisers. To address this need, the manufacturer is now offering a new database, Academic Index.

A twelve-month subscription to Academic Index or Magazine Index Plus costs $\$ 4,000$ a year.

This study is an attempt to examine both databases and determine which one is the better in an academic environment.

\section{Methodology}

First, the coverage of the journals included in Magazine Index Plus and Academic Index was closely examined.

Then, using a list of topics most frequently researched at the University of Indianapolis Library, 25 subjects were selected and searched in the February 1988 update of each database. The selection was done in such a way as to represent broad classi- 